\title{
What Matters Most? The Perceived Importance of Ability and Personality for Hiring Decisions
}

Cornell Hospitality Quarterly 52(2) 94-10I

(C) The Author(s) 2011

Reprints and permission:

sagepub.com/journalsPermissions.nav DOI: $10.1177 / 1938965510363377$

http://cqx.sagepub.com

@SAGE

\section{By Michael J.Tews, Kathryn Stafford, and J. Bruce Tracey}

\begin{abstract}
This study examined the emphasis hiring managers placed on general mental ability (GMA) and personality-agreeableness, conscientiousness, emotional stability, and extraversion-when evaluating applicant profiles for servers for a national restaurant chain. GMA was framed as either "intelligence" or the "ability to learn and solve problems." Under both conditions, GMA was valued, but less than agreeableness, conscientiousness, and emotional stability, even though GMA has been demonstrated to be the strongest predictor of employee performance. Framed as the "ability to learn and solve problems," GMA was more highly valued, but still less than personality.
\end{abstract}

\section{Keywords}

hiring decisions, general mental ability, personality

Hiring the right employees is critical for the success of any hospitality enterprise. Doing so for direct guest contact positions is particularly important because these employees are the boundary between the organization and its guests (Solomon et al. 1985). These employees' behavior immediately affects customer perceptions of service quality and satisfaction (Liao and Chuang 2004). Consequently, it is important for organizations to hire the best employees to meet the needs of their guests. For example, Doubletree Hotels has identified seven key attributes for selecting employees: practical learning, teamwork, tolerance for stress, sales ability, attention to detail, adaptability and flexibility, and motivation (Carbonara 1996). According to Carbonara (1996), Doubletree's hiring criteria reflect the common mantra for hiring hospitality employees, to wit: "Hire for attitude, train for skill." Fundamental to this mantra is a belief in hiring employees for attributes that cannot be easily trained and hiring employees who can be easily trained in company-specific skills.

It is easy to agree that hospitality organizations should hire the right people. What is not clear is whether managers base their hiring decisions on the attributes that have been demonstrated to be most predictive of job performance through research. If they did, then some of the industry's most endemic problems, such as high employee turnover and inconsistent service quality, could be more readily resolved. To explore this issue, this research will examine the relative importance managers place on general mental ability (GMA) as compared to the personality dimensions from the Big Five framework when determining employment suitability for potential guest contact employees.

We begin by discussing some of the evidence concerning the predictive validity of GMA and personality. Next, we discuss the limited research that has examined the importance managers place on GMA and personality in making hiring decisions. Then we delineate how the present study extends previous research and outline the research questions to be addressed. The next section discusses the methodology used in this study, followed by the results from a sample of managers directly involved in hiring decisions. Finally, we discuss the implications of our findings for improving hiring decisions and operational performance.

\section{The Predictive Validity of GMA and Personality}

Described as the ability to reason, plan, solve problems, think abstractly, comprehend complex ideas, and learn quickly (Gottfredson 1997), GMA has been demonstrated to be the strongest predictor of employee performance. GMA encompasses a number of cognitive abilities - including verbal, mathematical, and spatial abilities - that reflect a single, holistic intelligence construct (Gottfredson 2004; Ree, Earles, and Teachout 1994). While there is debate regarding the specific dimensions that may define GMA, there is consensus that "the general mental ability factor ... is a universal and reliably measured distinction among humans in their ability to learn, reason, and solve problems" (Gottfredson 2004, 35). The relationship between GMA and performance has been substantiated in numerous metaanalytic studies (e.g., Hunter 1986; Hunter and Hunter 1984; Ree and Earles 1992; Schmitt et al. 1984). Hunter and Hunter's (1984) meta-analysis, for example, estimated GMA-performance correlations to range from .58 for professional managerial jobs to .23 for unskilled jobs. These findings have led some to argue that GMA should be the primary 
basis for making all hiring decisions (Schmidt and Hunter 1998).

The dominant framework for examining the effect of personality on job performance is known as the Big Five model. The Big Five dimensions - agreeableness, conscientiousness, emotional stability, extraversion, and openness to experience-represent broad traits believed to encompass the range of normal personality. Individuals high in agreeableness tend to be altruistic, warm, generous, trusting, and cooperative. Those high in conscientiousness are typically efficient, punctual, well organized, and dependable. Emotionally stable individuals are generally calm, relaxed, and free from worry. Individuals high in extraversion are typically highly sociable, assertive, active, energetic, and talkative. Finally, those individuals high in openness tend to be imaginative, original, unconventional, and independent (Costa and McCrae 1992).

Hurtz and Donovan's (2000) meta-analysis of the Big Five and job performance demonstrated that personality does have a positive performance impact. In the context of customer service occupations, conscientiousness had the strongest relationship with performance $(r=.25)$, followed by agreeableness $(r=.17)$ and emotional stability $(r=.12)$. For those in sales, a related occupational group, conscientiousness $(r=.26)$, extraversion $(r=.15)$, and emotional stability $(r=.13)$ were significantly related to performance. Openness, however, was not a significant predictor of performance in either of these job categories.

In a hospitality-specific study, Tracey, Sturman, and Tews (2007) demonstrated the importance of GMA and conscientiousness for entry-level employees. ${ }^{1}$ This research demonstrated that GMA was a significant predictor of performance for newcomers (i.e., those employed less than six months). In addition, they found that the influence of GMA was substantially greater than the influence of conscientiousness during this initial period of employment. The regression coefficient for the impact of GMA on newcomer performance was $.37(p<.01)$; whereas the coefficient for conscientiousness was not significant at -.11 . For experienced employees (i.e., those employed longer than six months), the regression coefficient of .15 for the impact of GMA on job performance was not significant; whereas the coefficient for conscientiousness was .34 $(p<.01)$. These findings suggest that GMA is particularly important for entry-level hospitality employees during their initial period of employment when they are being trained and mastering the content of their jobs, while conscientiousness is particularly important afterwards once employees need to focus more on implementing performance standards. Consistent with general workplace research, GMA and conscientiousness were demonstrated to be two key employee attributes for predicting successful performance.

\section{Managerial Preferences When Making Hiring Decisions}

It has been argued that it is not enough to examine whether certain attributes predict performance (Schmitt and Chan 1998). Research should also focus on managers' beliefs in the value of such attributes. Such research serves as one avenue to assess alignment between research and practice. Alignment would suggest that managers are hiring individuals based on attributes that have been demonstrated to predict successful performance. Misalignment, on the other hand, would suggest the need for further research on the causes of such discrepancies and research on the effectiveness of various means to train managers on valid predictors of successful performance.

One piece of research in a nonhospitality context that focused on understanding the emphasis managers place on GMA and the Big Five in making hiring decisions was the work of Dunn et al. (1995). This study examined the influence of these attributes on managers' evaluations of hypothetical applicant profiles. Six groups of managers evaluated the employment suitability of applicants for one of six jobs-carpenter, insurance sales representative, licensed practical nurse, medical technologist, reporter, or secretary. Across jobs, they found that GMA and conscientiousness most strongly influenced the managers' employment suitability ratings, followed by emotional stability, openness, extraversion, and agreeableness. Given the weight placed on GMA and conscientiousness, these findings suggested that the managers had hiring preferences that would maximize employee job performance when applied to practice.

In more recent research in a hospitality context, Tews, Stafford, and Zhu (2009) found a different pattern of hiring policies with a sample of hotel managers. This study assessed the importance managers placed on GMA, the Big Five, gender, and physical attractiveness. Three groups of managers assessed the employment suitability of applicants for one of three jobs - front office associate, housekeeper, or maintenance engineer. For all jobs, conscientiousness most strongly influenced the managers' ratings, following by agreeableness, GMA, emotional stability, openness, attractiveness, extraversion, and then gender. This study suggests that hospitality managers place less emphasis on GMA than managers in other industries, but they place similar emphasis on conscientiousness.

We contend that there are at least three major reasons why managers in the hospitality industry place more weight on personality than on GMA. Given that a large proportion of hospitality employees' work is interpersonal and that such performance may be more a function of individuals' habits and skills rooted in personality (Motowidlo, Borman, and Schmit 1997), managers may emphasize personality more 
than GMA. Another related reason why managers may place a higher value on personality is that they incorrectly underestimate the importance of cognitive knowledge and skills that are required for successful performance, especially for entry-level positions (Schmidt 2002). Part of this view may be linked to the "low wage, low skill" sentiment that is still commonly used to describe employment in the hospitality industry. This perception reinforces the assumption that GMA, or raw intelligence, is not particularly important in the hospitality industry. Moreover, negative traits such as social ineptitude or impracticality may be commonly associated with intelligent people, albeit incorrectly, and reduce the value placed on GMA (Rynes, Brown, and Colbert 2002). This negative disposition toward intelligence may provide an additional explanation of the preference for personality.

\section{Restaurant Hiring Decisions}

This study aims to further examine how hospitality managers make hiring decisions based on GMA and personality dimensions from the Big Five. The study seeks to determine the generalizability of Tews, Stafford, and Zhu's (2009) findings by extending this research with another sample and a different segment of the hospitality industry, namely, the restaurant segment. The study will also examine how framing GMA influences the importance managers place on this attribute. Finally, this study will ascertain whether there are distinct subsets of managers that value GMA and personality differently.

As discussed above, hospitality managers may emphasize different applicant attributes in determining employment suitability than do managers in other industries. Research in the area has been quite limited, however. Thus, is it important to examine how hospitality managers value GMA and personality in determining employment suitability.

Question 1: What is the emphasis managers place on GMA and different dimensions of personality in assessing employment suitability?

Regardless of the method used to measure GMA (e.g., standardized test or interview questions), the language used by an organization to characterize this attribute may influence managers' perceptions of its relevance. That is, the way that GMA is framed could affect the emphasis managers place on it. While there are multiple cognitive dimensions subsumed under GMA, holistically GMA is often referred to as "intelligence" or the "ability to learn and solve problems" in lay language (Hunter and Schmidt 1996; Schmidt 2002). Schmidt (2002) argues that referring to GMA as "intelligence" has disadvantages because it implies innate potential and not a developed ability, which more correctly characterizes GMA. In addition, as noted above, individuals may ascribe negative traits to intelligent people (Rynes, Brown, and Colbert 2002). Referring to GMA as the "ability to learn and solve problems" might have advantages because managers may perceive a more direct relationship to performance, and such a characterization might not be associated with negative traits. Describing GMA as the "ability to learn and solve problems" when presenting applicant qualifications may thus increase the emphasis managers place on this attribute.

Question 2: Does the framing of GMA affect the emphasis managers place on this attribute in assessing employment suitability?

Previous research generally assumes that there is consistency among managers in the value they place on applicant attributes. That is, it is assumed that managers value the same characteristics in applicants. As in all human behavior, however, there will be some variability in the emphasis different managers place on different applicant attributes. The question arises whether this variability is random and small or systematic and large. If there are systematic and large differences across managers, there may be distinct subsets of managerial preferences.

Question 3: Are there distinct subsets of managers who value GMA and personality differently in assessing employment suitability?

\section{Sample and Procedures}

To answer the research questions, we conducted a study that focused on assessing employment suitability for servers, with an organization that owns and operates approximately 120 casual-theme restaurants in the United States. Based on the company-wide job description and performance appraisal, a server's primary job responsibilities in this context include interacting professionally with guests, suggestive selling and demonstrating product knowledge, serving food, cash handling, resolving guest complaints, cooperating with and assisting coworkers, taking direction from others, working with a sense of urgency, and willingly taking on additional duties. The current system for selecting servers includes the review of applications, interviews, and reference checks. The organization currently does not use standardized GMA and personality assessments in its selection protocol for servers. In this organizational context, selection based on GMA and the Big Five is not explicit, yet managers may assess these attributes through less direct methods such as interviews or reference checks.

Policy capturing, also known as conjoint analysis, was used to examine the implicit weight managers place on 
GMA and personality. This methodology has been used in a wide variety of organizational studies to determine how individuals integrate different information in decision making (Karren and Barringer 2002), including studies similar to this one. In policy capturing, raters are presented with a series of hypothetical scenarios where the independent variables of interest are manipulated at different levels. For this study, managers were provided with a series of applicant profiles with different degrees of GMA and personality. Managers then evaluated each profile by indicating the extent to which each applicant should be hired. To determine the importance the managers placed on GMA and personality, the evaluations were regressed on the different combinations of GMA and personality. The regression coefficients indicate the relative emphasis, or weight, managers place on the applicant attributes. These weights reflect the managers' hiring policies or preferences. ${ }^{2}$

One hundred and four managers from one of the organization's four regional divisions evaluated applicant profiles, representing approximately 80 percent of the managers within this division. All of the managers had employee hiring responsibilities. Field human resources managers administered the surveys to the managers on-site in their restaurants. The average age of the managers was 37.4 years old $(S D=8.5)$, and the managers averaged 13.4 years of experience $(S D=7.3)$. The managers' average organizational tenure was 3.9 years $(S D=3.7)$. Seventy-two percent of the managers were male, and 88 percent were Caucasian.

The managers rated thirty-six server applicant profiles, which were developed by combining high and low levels of GMA, agreeableness, conscientiousness, emotional stability, and extraversion. These five attributes with two levels resulted in thirty-two unique applicant profiles. Four profiles were randomly duplicated to serve as practice profiles to acclimate the managers to the rating process (not included in the analyses), resulting in thirty-six total profiles. The descriptions of the personality dimensions were drawn from previous research (Gosling, Rentfrow, and Swan 2003). The high and low levels for the personality dimensions were described, respectively, as (1) "sympathetic, warm" and "critical, quarrelsome" for agreeableness; (2) "dependable, self-disciplined" and "disorganized, careless" for conscientiousness; (3) "calm, emotionally stable" and "anxious, easily upset" for emotional stability; and (4) "extraverted, enthusiastic" and "quiet, reserved" for extraversion. GMA was characterized either as (1) "intelligent" and "unintelligent" or (2) "quick to learn and solve problems" and "slow to learn and solve problems." Under random assignment, approximately half of the managers evaluated profiles under each GMA framing condition.

Openness was omitted in creating the applicant profiles for several reasons. First, this dimension has not been shown to be a strong predictor of job performance (Hurtz and Donovan 2000), and previous research has demonstrated that hospitality managers do not highly value this attribute (Tews, Stafford, and Zhu 2009). Second, including another dimension would have doubled the number of unique profiles to evaluate (from thirty-two to sixty-four), and thus might have taxed the respondents and jeopardized survey completion. Moreover, our research sponsor was sensitive to the time required to complete the assessment of applicant profiles.

For each applicant profile, the managers indicated the extent to which they agreed that the applicant should be hired. A 7-point scale was used with anchors ranging from 1 (strongly disagree) to 7 (strongly agree). The managers were informed that one of the challenges they might encounter was making judgments about job applicants based on limited information. It was stated that in reality, hiring decisions may be based on a variety of additional attributes, such as previous experience, communication skills, and scheduling availability. As such, the managers were instructed to assume that all of the applicants met minimum requirements and were equivalent on such attributes. A sample applicant profile is presented in Exhibit 1.

Confidentiality of responses was assured both orally and in writing (i.e., in the survey instructions). The field human resources managers instructed the respondents to place their completed surveys in an envelope and seal it before giving it back to them. The field human resources managers then returned the sealed envelopes to the lead author. Only the research team had access to the managers' surveys.

\section{Results}

Ordinary least squares (OLS) regression was used to capture the individual managers' policies. Each manager's evaluations were regressed on the attributes of the hypothetical applicants to estimate policy weights, for a total of 104 regressions. Employment suitability was specified as a function of GMA, agreeableness, conscientiousness, emotional stability, and extraversion. The lower level of each attribute was coded 0 and the higher level was coded 1. For example, with respect to extraversion, "quiet, reserved" was coded 0 and "extraverted, enthusiastic" was coded 1 . The resulting regression coefficients, or policy weights, can be interpreted as the difference in employment suitability preference associated with an applicant's having a high level of the attribute rather than a low level.

The $F$-statistics for the policy equations for 100 of the 104 managers were significant $(p<.05)$, and the $R^{2}$ s ranged from .33 to .99 . A significant $F$-statistic for a manager's policy equation indicated the existence of a consistent policy on the part of that manager in evaluating the profiles (Cooksey 1996). The absence of a significant $F$-statistic for a manager's policy equation indicated that the information presented in the applicant profiles did not have a significant 


\section{Exhibit 1:}

Example Applicant Profile

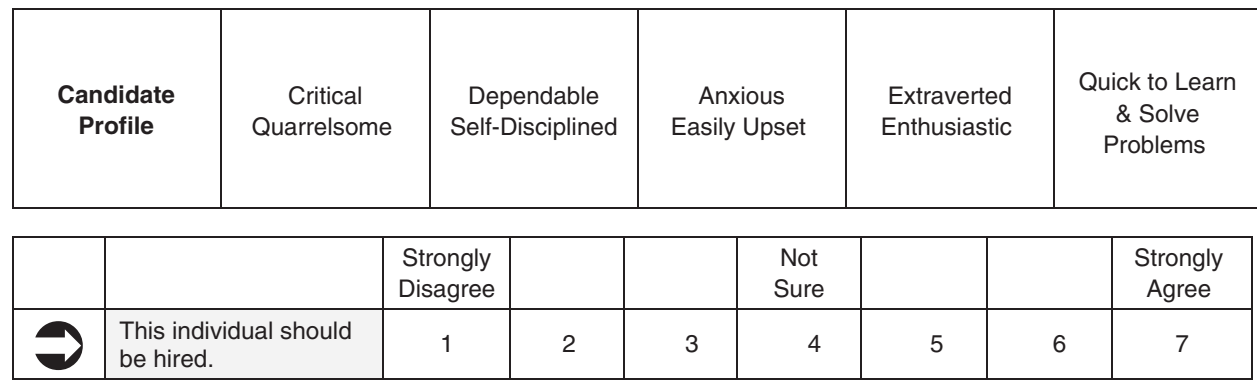

\section{Exhibit 2:}

\section{Manager Policy Weights}

\begin{tabular}{|c|c|c|c|c|c|c|}
\hline & & & & & & \\
\hline & & & & & Ability & \\
\hline & Mean Weight & SD & Mean Weight & SD & Mean Weight & SD \\
\hline GMA $(g)$ & $.25_{\mathrm{acn}}$ & .16 & $.2 \mathrm{I}_{\mathrm{acn}}$ & .17 & $.29_{\mathrm{ac}}$ & .15 \\
\hline Agreeableness (a) & $.49_{\text {cegn }}$ & .19 & $.54_{\text {cegn }}$ & .19 & $.44_{\mathrm{eg}}$ & .18 \\
\hline Conscientiousness (c) & $.35_{\mathrm{aeg}}$ & .16 & .32 & .15 & $.38_{\mathrm{eg}}^{\mathrm{gg}}$ & .16 \\
\hline Emotional stability (n) & $.34_{\text {aeg }}^{\text {deg }}$ & .18 & $.33_{\mathrm{aeg}}^{\mathrm{deg}}$ & .17 & $.34_{\mathrm{e}}^{6}$ & .20 \\
\hline Extraversion (e) & $.20_{\mathrm{acn}}^{\mathrm{acg}}$ & .19 & $.20_{\mathrm{acn}}^{\mathrm{acg}}$ & .18 & $.20_{\mathrm{acn}}$ & .21 \\
\hline n 100 & & 47 & & 53 & & \\
\hline
\end{tabular}

Note: Policy weights are the average standardized regression coefficients across managers. The SDs are the standard deviations of the standardized regression coefficients across managers. Subscripts denote significantly different weights using a cumulative Type I error rate below .05 (i.e., a Bonferroni adjustment) within each cluster.

influence on the manager's decision making (Cooksey 1996). Accordingly, the 4 nonsignificant policy equations were not used to answer the research questions. The average manager policy weights - the average of the individual managers' regression coefficients - were examined to test the hypotheses. These policy weights are presented in Exhibit 2.

Question 1 asked what is the relative emphasis managers placed on GMA and the different dimensions of personality in assessing employment suitability. To answer this question, the average policy weights were tested for significant differences using two-tailed, within-sample tests of differences in means, using a Bonferroni adjustment for multiple comparisons. For the overall sample, the most emphasis was placed on agreeableness followed by conscientiousness, emotional stability, GMA, and extraversion. All pairwise differences were significant at the .05 level with two exceptions. The emphasis placed on GMA was not significantly different from that placed on extraversion, and the emphasis placed on conscientiousness was not significantly different from that placed on emotional stability. In the intelligence subsample, the pattern of results was the same as with the overall sample. In the ability subsample, a different pattern emerged. The relative importance placed on the attributes was the same, but there were fewer significant differences. In addition to the two nonsignificant differences in the overall sample, there were nonsignificant differences between emotional stability and GMA, emotional stability and agreeableness, and agreeableness and conscientiousness.

Question 2 asked what impact the framing of GMA would have on the emphasis managers placed on this attribute. This question was examined by assessing the significance of the difference between GMA policy weights for managers when GMA was presented as the "ability to learn and solve problems" versus policy weights for managers when GMA was presented as "intelligence" using a two-tailed between-sample test of difference in means. The GMA weight in the "ability" subsample was .08 higher $(p<.01)$.

Question 3 asked whether the managers had the same general policies or whether some managers placed different emphasis on certain attributes in determining employment suitability. To answer this question, a cluster analysis was performed. ${ }^{3}$ Three subsets of managers emerged, as presented in Exhibit 3. These subsets indicate that the applicant 


\section{Exhibit 3:}

Clusters of Manager Policy Weights

\begin{tabular}{|c|c|c|c|c|c|c|}
\hline & \multicolumn{2}{|c|}{ Cluster I } & \multicolumn{2}{|c|}{ Cluster 2} & \multicolumn{2}{|c|}{ Cluster 3} \\
\hline & Mean Weight & SD & Mean Weight & SD & Mean Weight & SD \\
\hline GMA (g) & $.28_{\text {cen }}$ & .16 & $.09_{\mathrm{acn}}$ & .10 & $.33_{\mathrm{a}}$ & .13 \\
\hline Agreeableness (a) & $.35 \mathrm{e}$ & .14 & $.74_{\text {cegn }}$ & .12 & $.45_{\mathrm{cgn}}^{\mathrm{a}}$ & .12 \\
\hline Conscientiousness (c) & $.4 \mathrm{I}_{\mathrm{eg}}^{\mathrm{e}}$ & .18 & $.25_{\mathrm{aeg}}^{\operatorname{cogn}}$ & .12 & $.37_{\text {an }}^{\operatorname{cgn}}$ & .13 \\
\hline Emotional stability (n) & $.47_{\mathrm{eg}}^{\mathrm{eg}}$ & .18 & $.26_{\text {aeg }}^{\text {aeg }}$ & .15 & $.27_{\mathrm{ace}}^{\mathrm{an}}$ & .14 \\
\hline Extraversion (e) & $.05_{\mathrm{acgn}}^{\mathrm{eg}}$ & .12 & $.12_{\mathrm{acn}}^{\mathrm{aeg}}$ & .14 & $.36_{n}$ & .13 \\
\hline$n_{\text {overall }}$ & 34 & & 25 & & $4 I^{n}$ & \\
\hline$n_{\text {intelligence subsample }}$ & 12 & & 17 & & 18 & \\
\hline$n_{\text {ability subsample }}$ & 22 & & 8 & & 23 & \\
\hline
\end{tabular}

Note: Policy weights are the average standardized regression coefficients across managers. The SDs are the standard deviations of the standardized regression coefficients across managers. Subscripts denote significantly different weights using a cumulative Type I error rate below .05 (i.e., a Bonferroni adjustment) within each cluster.

attributes were not uniformly valued across the managers. In first subset, the managers moderately valued each of the applicant attributes with the exception of extraversion, which was hardly valued at all. In the second subset, the managers valued agreeableness extremely while devaluing GMA and extraversion extremely. Finally, in the third subset, the managers moderately valued each of the applicant attributes. This balanced subset had the most managers, followed by subset 1 and subset 2. Regarding demographic characteristics, the managers across the three clusters differed only by gender $\left(\chi^{2}=6.89, p<.05\right)$. There were more females than expected in the second and third clusters and fewer females than expected in the first cluster.

\section{Discussion and Implications}

The results from this study suggest that restaurant managers may not be making the most effective hiring decisions. While GMA has been consistently demonstrated to be the strongest predictor of job performance, it was not highly valued by the managers in this study. Three of the personality dimensions were consistently emphasized more-agreeableness, conscientiousness, and emotional stability. Of the personality dimensions, conscientiousness is the strongest predictor of performance, but the managers more highly valued agreeableness. These results for restaurant managers are generally consistent with the hotel managers' hiring preferences for front office associates, housekeepers, and maintenance engineers (Tews, Stafford, and Zhu 2009). Both samples emphasized personality more than GMA, but the hotel managers valued conscientiousness more than agreeableness.

The cluster analyses revealed that some groups of managers may be making better hiring decisions in practice than others. While none of the three clusters placed the most emphasis on GMA, managers in two of the clusters valued GMA approximately as much as the personality dimensions. These managers may be making reasonably effective hiring decisions. One group of mangers, however, may be particularly prone to making less than optimal hiring decisions by placing an extreme emphasis on agreeableness and little emphasis on GMA. The fewest managers, though, were in this subset.

Our study did not examine why the managers in this study failed to place a greater emphasis on GMA. As discussed beforehand, though, managers often underestimate the jobspecific knowledge and skill requirements in entry-level jobs and thus downplay the importance of GMA. This underestimation might have occurred in the present context. The managers may also have valued personality more because they may highly value such behaviors as helping others and being reliable and believe personality influences such behaviors. Validity studies support their belief (Hurtz and Donovan 2000). That said, GMA may impact these behaviors as well (Bergman et al. 2008). Further demonstrating these relationships would thus be a fruitful avenue for future research.

One important finding from this study is that the characterization of GMA influences its importance when managers determine a candidate's employment suitability. While overall GMA was not the strongest attribute influencing the managers' decisions, the results demonstrated that the appropriate framing of GMA enhances the weight managers place on this attribute. That is, when GMA is presented as the "ability to learn and solve problems" in contrast to "intelligence," GMA is more highly valued. The managers may have weighted GMA more heavily because this characterization may not have the negative connotations associated with "intelligence." Furthermore, the "ability" characterization may have been more highly valued because it relates to a specific ability necessary for successful job performance. A key implication of this finding is that organizations need to appropriately frame GMA (i.e., use appropriate vocabulary) to help ensure maximum 
acceptance of the importance of this attribute and of corresponding selection tools used in the employee hiring process.

Training could be a useful means to increase the importance managers place on GMA when hiring. Such training could address the importance of knowledge and skill in facilitating employee performance and how GMA is the primary means though which knowledge and skills are acquired. The independence of GMA relative to personality could also be addressed in such training. That is, it should be emphasized that hiring employees based on GMA does not mean that one cannot also hire individuals with desirable personality characteristics, such as conscientiousness, emotional stability, and agreeableness. Furthermore, training could focus on valid means to select employees based on GMA, such as through standardized GMA assessments like the Wonderlic Personnel Test (Wonderlic 1999), situational judgment tests (McDaniel et al. 2001), and situational and behavioral interviewing questions (Salgado and Moscoso 2002).

A number of future research opportunities are suggested here. The primary limitation of policy capture methodology (such as this study) is the evaluation of hypothetical profiles. Therefore, it might be useful to examine GMA and personality profiles of hired and nonhired employees to infer selection decisions in practice. In addition, further research could enhance the generalizability of our results by replicating this research in other organizations and other service occupations. Research also could also assess the influence of GMA in selection decisions across organizations where service levels and the degree of autonomy and decision-making authority afforded to employees vary, that is, where the cognitive demands required of service employees differ.

Hiring the right employees to meet the needs of our guests in the hospitality industry is of critical importance. It appears, however, that the most valid applicant attributes are not always the most highly valued by hiring managers. To help ensure that the best employees are hired in practice, organizations should carefully delineate hiring criteria in line with research evidence and properly train hiring managers on effective recruiting and selection. Through efforts such as these, we can see a better alignment between research and practice and ultimately realize better employee performance, guest satisfaction, and organizational results.

\section{Notes}

1. While this research assessed the impact of conscientiousness on performance, the impact of the remaining four dimensions of the Big Five was not a focus of this study.

2. See Aiman-Smith, Scullen, and Barr (2002) and Karren and Barringer (2002) for thorough discussions on designing and conducting policy-capture studies.

3. The managers' policy weights were initially subjected to hierarchical cluster analysis to determine outliers and an initial number of clusters. An agglomerative procedure was used, and the distance between observations was measured as the squared Euclidean distance. Ward's method was selected as the clustering rule. Following the hierarchical clustering, cases were allocated to three clusters using $k$-means cluster analysis.

\section{References}

Aiman-Smith, L., S. E. Scullen, and S. H. Barr. 2002. Conducting studies of decision making in organizational context: A tutorial for policy-capturing and other regression-based techniques. Organizational Research Methods 5:388-414.

Bergman, M. E., M. A. Donovan, F. Drasgow, R. C. Overton, and J. B. Henning. 2008. Test of Motowidlo et al.'s (1997) theory of individual differences in task and contextual performance. Human Performance 21:227-53.

Carbonara, P. 1996. Hire for attitude, train for skill. Fast Company 4:73-81.

Cooksey, R. W. 1996. The methodology of social judgment theory. Thinking \& Reasoning 2:141-71.

Costa, P. T., and R. R. McCrae. 1992. Revised NEO personality inventory (NEO PI-R) and NEO five-factor inventory (NEOFFI) professional manual. Lutz, FL: Psychological Assessment Resources, Inc.

Dunn, W. S., M. K. Mount, M. R. Barrick, and D. S. Ones. 1995. Relative importance of personality and general mental ability in managers' judgments of applicant qualifications. Journal of Applied Psychology 80:500-509.

Gosling, S. D., P. J. Rentfrow, and W. B. Swann. 2003. A very brief measure of the Big-Five personality domains. Journal of Research in Personality 37:504-28.

Gottfredson, L. S. 1997. Intelligence and social policy. Intelligence 24:1-12.

Gottfredson, L. S. 2004. Schools and the g factor. The Wilson Quarterly, Summer, pp. 35-45.

Hunter, J. E. 1986. Cognitive ability, cognitive aptitudes, job knowledge, and job performance. Journal of Vocational Behavior 29:340-62.

Hunter, J. E., and R. F. Hunter. 1984. Validity and utility of alternate predictors of job performance. Psychological Bulletin 96:72-98.

Hunter, J. E., and F. L. Schmidt. 1996. Intelligence and job performance: Economic and social implications. Psychology, Public Policy, and Law 2:447-72.

Hurtz, G. M., and J. J. Donovan. 2000. Personality and job-performance: The Big Five revisited. Journal of Applied Psychology 85:869-79.

Karren, R. J., and M. W. Barringer. 2002. A review and analysis of the policy-capturing methodology in organizational research: Guidelines for research and practice. Organizational Research Methods 5:337-61.

Liao, H., and A. Chuang. 2004. A multilevel investigation of factors influencing employee service performance and customer outcomes. Academy of Management Journal 47:41-58.

McDaniel, M., Morgeson, F. P., Finnegan, E. B., Campion, M. A., and Braverman, E. P. (2001). Use of situational judgment tests 
to predict job performance: A clarification of the literature. Journal of Applied Psychology, 86, 730-740.

Motowidlo, S. J., W. C. Borman, and M. J. Schmit. 1997. A theory of individual differences in task and contextual performance. Human Performance 10:71-83.

Ree, M. J., and J. A. Earles. 1992. Intelligence is the best predictor of job performance. Current Directions in Psychological Science 1:86-89.

Ree, M. J., J. A. Earles, and M. S. Teachout. 1994. Predicting job performance: Not much more than g. Journal of Applied Psychology 79:518-24.

Rynes, S. L., K. G. Brown, and A. F. Colbert. 2002. Seven common misconceptions about human resource practices: Research findings versus practitioner beliefs. Academy of Management Executive 16:92-103.

Salgado, J. F., \& Moscoso, S. (2002). Comprehensive metaanalysis of the construct validity of the employment interview. European Journal of Work and Organizational Psychology, 11, 299-324.

Schmidt, F. L. 2002. The role of general cognitive ability and job performance: Why there cannot be a debate. Human Performance 15:187-210.

Schmidt, F. L., and J. E. Hunter. 1998. The validity and utility of selection methods in personnel psychology: Practical and theoretical implications of 85 years of research findings. Psychological Bulletin 124: 262-74.
Schmitt, N., and D. Chan. 1998. Personnel selection: A theoretical approach. Thousand Oaks, CA: Sage.

Schmitt, N., R. Z. Gooding, R. A. Noe, and M. Kirsch. 1984. Metaanalyses of validity studies published between 1964 and 1982 and the investigation of study characteristics. Personnel Psychology 37:407-22.

Solomon, M. R., C. Surprenant, J. A. Czepiel, and E. G. Gutman. 1985. A role theory perspective on dyadic interactions: The service encounter. Journal of Marketing 49:99-111.

Tews, M. J., K. Stafford, and J. Zhu. 2009. Beauty revisited: The impact of attractiveness, ability, and personality in the assessment of employment suitability. International Journal of Selection and Assessment 17:92-100.

Tracey, J. B., M. C. Sturman, and M. J. Tews. 2007. Ability versus personality: Factors that predict employee job performance. Cornell Hotel and Restaurant Administration Quarterly 48:313-22.

Wonderlic, Inc. (1999), Wonderlic personnel test \& scholastic level exam user's manual, Libertyville, IL: Author.

\section{Bios}

Michael J. Tews is an assistant professor in the School of Hospitality Management at Penn State University (mjt17@psu.edu). Kathryn Stafford is an associate professor in the College of Education and Human Ecology at Ohio State University (stafford.2@, osu.edu). J. Bruce Tracey is an associate professor in the School of Hotel Administration at Cornell University (jbt6@cornell.edu). 